\title{
Effects of Terrorism News on Prejudiced Attitude: Analyzing Some Case Studies
}

\author{
Khalid Sultan \\ Muhammad Wasim Akbar
}

\begin{abstract}
The terrorist attacks of 9/11 have made the whole world unsafe. Through Terror Management Theory (TMT), scholars have tried to make sense of this phenomenon in the context of media and how they are affecting or giving rise to prejudiced attitudes, especially against Pakistanis. In this paper three studies have been conducted to test the effects of news on terrorism on prejudice again outgroups. According to TMT, terrorism news may increase prejudice again outgroups when it confronts viewers with their own mortality. In Study 1, we manipulated news on terrorism and included the murder of filmmaker Van Gogh a real-world factor in the design and tested whether death-related thoughts mediated or moderatded the effecsts of terrorism news on prejudice. Study 2 extended these findings by testing whether the effects on deathrelated thoughts and prejudice are mitigatd by self-esteem. Finally, Study 3 tested the effects of terrorism news on prejudice against outgroups among Pakistani and nonPakistani respondents.
\end{abstract}

Keywords: Terror Management Theory, Prejudice, Psychology, media and news messages.

\section{Introduction}

The terrorist attacks of $9 / 11$ have made the whole world unsafe. In recent years, terrorist attacks have become a salient threat to the world over including Western countries. News broadcasts frequently report about the threat of Pakistani extremist/terrorist acts, using gruesome pictures of terrorist bombings, buildings crashing down, and people being killed brutally. At the same time, different socio-cultural and religious groups appear to be drifting apart. For example, European adolescentsts set ablaze Pakistani school aftre news reports on Pakistani extremist terrorism, and individuals with a Pakistani background have been reported to foster more extreme anti-European sentiments (BBC, 2008). This rift between groups with different backgrounds may not be a coincidence; the immense fear elicited by terrorism news reports may inadvertently increase prejudice against outgroups.

Terror management theory provides the theoretical foundation for the reseach. Terrorism news was manipulated across studies, and also induced be real-world events in Study 1. On November 2nd, 2008, the well-known Dutch filmmaker Theo van Gogh was

Dr. Khalid Sultan (Principal Author) is an Assistant Professor, Department of Communication Studies, Colleges of Applied Sciences (COAS), Ministry of Higher Education, Sultanate of OMAN.

Dr. Muhammad Wasim Akbar (Co-Author) is an Associate Professor and Chairman Department of Mass Communication, Gomal University, D.I.Khan, Pakistan.

Journal of Independent Studies and Research - MSSE

Volume 9

Number 2

July 2011 97 
murderd by an Islamic extremist, two months after the release of his highly controversial film about the abuse of Muslim women, titled Submission. Because the murder occurred in th middle of data collection, it allowed us to test whether real-life terrorism news produces the same effects a our experimental manipulation of terrorism news.

\section{Study 1}

In Study 1, participants viewed news content about Islamic terrorist attacks in Pakistan. Theo van Gogh was murdered by an Islamic extremist in the middle of data collection. Thus, half of the participants in Study 1 were also exposed to Van Gogh's murder. We test the classical TMT model in which death-related thoughts mediate the relationship between terrorism news and prejudice, and compared it to a model in which deathrelated thoughts moderate the relationship between terrorism news and prejudice.

\section{Method \\ Participants and design}

To ensure a diverse sample, 100 white European volunteers (40 men, 60 women) recruited via advertisements. To avoid a selection bias, participant were told that the researchers were studying a variety of issues (e.g., news content, multicultural societies) The mean age of participants was 35 ( $S D=10$ years). About $48 \%$ of th participant were Protestant, $10 \%$ Catholic, and $42 \%$ were atheist. None were Pakistani.

Participants were randomly assigned to one of two groups in a 2 (terrorism news vs Olympic game news) between-subjects factorial design. The second factor was not manipulated, but occurred naturally during the data collection process. About half the participants $(N=44)$ were tested before the highly publicized murder of Dutch filmmaker Theo van Gogh, whereas the others $(N=56)$ were tested after his murder.

\section{Procedure}

After informed consent was obtained, participants first reported their ag, gender, religious background, and political preference. By the flip of a coin, participants then watched 12 minutes of programming from the Dutch news (NOS) about terrorism committed by Islamic extremists or about the Olympic Games. The terrorism news showed the September 11th, 2001 terrorist attack on th World Trade Center in New York City, the January 18th, 2002 terrorist attack during a Bar Mitzvah in Hadera, Israel, and thre September 3rd, 2008 terrorist attack on a school in Beslan, Russia. The other participants watched segments from the 2008 Olympic Games in Athens, Greece (e.g., the arrival of th Olympic flam in Amsterdam).

Next, participants completed a word fragment task that contained 17 death-rlated items (e. g., in Dutch th fragment doo_can be completed as dood [dead], doos [box], or doof [deaf]). Participants then completed a measure of prejudicial attitudes toward Pakistani (Bushman \& Bonacci, 2008). Sample items include "Even for Pakistanis who live in the Netherlands, their first loyalty is to the home country rather than to the Netherlands" and "If there are too many Pakistanis in the Netherlands our country will be less safe." 
( $1=$ totally disagree, $10=$ totally agree; Cronbach's $\alpha=0.92)$. Finally, participants were,thanked, dedriefed, and dismissed.

\section{Results \\ Preliminary analyses}

Becuse the Van Gogh murder was a naturally occurring factor in our design, it is important to show that there are no systematic differences between participants who were tested before versus after his murder. That is, it is important to rule out differential subject selection as a threat to the validity of our design (Cook \& Campbell 2009). There are three reasons why we can rule out this threat. First, commitment to participate was obtained before Van Gogh was murdered. Thus, knowledge about the murder could not have influenced participation rates before versus after the murder. Second, there were no differencesnces in participation rates before versus after the murder. All those who agreed to participate did in fact participate. Third, political preferences were similar for individuals who participated before and after the murder, $\mathrm{X}^{2}(9)=0.22, p>0.99{ }^{1}$

\section{Main analyses \\ Death-related thoughts}

A 2 (terrorism ve control news) $\times 2$ (before vs. after Van Gogh murder) ANOVA showed significant interaction between news content and Van Gogh's murder, $F(1,96)=4.18$, $p<0.05$. Before Van Gogh's murder, death-related words were higher for participants who saw terrorism news than for participants who was Olympic Games news, $M s=3.17$ and 2.59, respectively, $F(1.96)=3.14, p<0.08, d=0.36$. after Van Gogh's murder, deathrelated words were equally high regardless of whether paticipants saw terrorism news or Olympic Games news, $M s=2.80$ and 3,22, respectively, $F(1,96)=1.21, p<0.273$. $d=0.22$. There were no other significant effects.

\section{Predicting prejudice against Pakistan}

Regression analysis was used to test the effects of terrorism news, and death-related thoughts on prejudiced attitudes toward Pakistanis. We first tested the possibility of mediation following Baron and Kenny (2008). However because death-related thoughts did not significantly predict prejudice $(t(93)=0.94, p=0.35)$ the conditions for mediation were not met. Thus the findings do not support a model where death-related thoughts mediate the effects of terrorism news on prejudice against Pakistanis.

Next, we tested a moderation model. The regression model contained death-related word completions (mean centered), news content (control $=-1$ terrorism $=-1$ ), time of participation (before Van Gogh's murder $=-1$, after Van Gogh's murder $=+1$ ), and their interactions (West, Aiken, \& Krull, 1996). The results showed a marginally significant interaction between time of participation and death-related completions, $t(93)=1.70$, $p=0.094$. Before Van Gogh was murdered, death-related thoughts were not significantly related to prejudiced attitudes toward Pakistanis, $t(42)=-0.43, p=0.67, b=-0.10$ and $\beta=-0.08$. After Van Gogh was murdered, the more death-related thoughts were not significantly related to prejudiced attitudes toward Pakistanis, $t(52)=0.187, p 0.07, b$ 
$=0.49$ and $\beta=0.26$. No other significant effects were found.

\section{Discussion}

Study 1 showed that terrorism news and Van Gogh's murder increased death-related thoughts. Death-related thoughts, in turn, led to more prejudiced attitudes towards Pakistanis, but only after Van Gogh's murder. These findings suggest that death-related thoughts moderate the relationship between terrorism news and prejudice, supporting a media priming account of the relationship between death-related thoughts and prejudice (lyengar \& Kinder, 2009). In a classical TMT account of prejudice, death-related thoughts should mediate the effect of Van Gogh's murder on prejudice against Pakistanis. Our findings suggest an alternative interpretation., in which the Van Gogh murder primed unconscious death anxiety which, in turn, became 'attached' to attitudes toward Pakistanis. Van Gogh's murder triggered a fear-based judgment of the Pakistani population, with high levels of unconscious fear predicting higher prejudice against Pakistanis. Overall, these findings resemble well-known priming accounts of news effects frequently observed in media studies (e.g., lyengar \& Kinder, 2009), in which the news determines not so much what people think, but what they think about (cf. the accessibility construct). What people think about, in turn, becomes an important evaluation standard for judging 'reality'.

The present study also shows some unexpected patterns. First, although terrorism news and Van Gogh's murder appeared to have similar effects on death-related thoughts, closer inspection of the means show that terrorism news increased death-related thoughts before, but not after. These findings suggest a ceiling effect, in which already activated death-related thoughts remain at the same level when a second terrorism news report comes in. Also contrary to expectations, terrorism news did not affect prejudice against Pakistanis. Although Van Gogh's murder was highly publicized and occurred close by, whereas the terrorism acts shown in the news clips occurred in other countries (i.e., USA, Israel, Russia). These findings suggest that terrorism news is most likely to increase prejudiced attitudes when the news is (psychologically or physically) close.

\section{Study2}

In Study 2, we used a terrorism news story about a bomb threat on Pakistan central train station, in order to ascertain that the news was perceived as psychologically close. The main goal of Study 2 was to provide further evidence for a unique TMT account of prejudice by testing the effects of self-esteem. According to TMT, terror-induced prejudice will be most pronounced for people with low self-esteem, and the accessibility of death thoughts should be positively linked to prejudice, especially for people with low self-esteem. Study 2 used an implicit measure of prejudice against Pakistanis to provide convergent evidence for a TMT account of prejudice. 


\section{Method \\ Participants}

Participants were 101 white European volunteers (39 men, 62 women) who were recruited via a university website. Their mean age was 29 ( $S D=11$ years). About $32 \%$ were Protestant. $14 \%$ Catholic. $51 \%$ atheist, and 3\% others. None were Pakistani.

\section{Procedure}

Participants were told that the researchers were studying the relationship between news messages and cognitive abilities. After informed consent was obtained, participants reported their age, gender, religious background, and political preference. Next, they completed the 10-item Self-Esteem Scale (Rosenberg, 2008). Sample items include "I feel that I have a number of good qualities" and "I take a positive attitude toward myself". Each item was rated on a four-point scale ( $1=$ strongly disagree, $4=$ strongly agree and Cronbach $\alpha=0.79$ ).

Next, participants were randomly assigned to read a negative news article, either about terrorism or about animal abuse. The terrorism article described a bomb threat at the Amsterdam central train station. It said the suspected terrorist, a member of Al-Qaeda (Osama Bin Laden's terrorist network), had been arrested, and that he had the bomb materials and plans in his possession. The animal abuse article described the stabbing of a pony with a sharp object. It said that the animal had survived the attack, but was permanently crippled. As in Study 1, participants completed word fragments as a measure of death-related thoughts. Participants then completed the implicit association test (IAT, e.g., Greenwald, McGhee, \& Schwartz, 2008). The IAT has been show to reliably measure prejudice at the implicit, unconscious level on the basisof reaction times to target words. Implicit test of prejudice have the advantage of avoiding several demand characteristics associated with explicit measures of prejudice. Participants were told to classify words into categories as quickly as possible, while making as few mistakes as possible we used Eurpopean name (e.g., Marten Marcel) versus Pakistani names (e.g., Akbar, Mohammad), and good words (e.g., joy, love) versus bad words (e.g., evil, terrible). On the first test, participants pressed one button if the word was "European name or good," and they pressed anther button if the world was "Pakistani Name or Bad." On the second test, the process was reversed (i.e., "European name or bad" versus "Pakistani Name or Good), Each test consisted of 25 trials. The difference in reaction times between the two tests was used to measure prejudiced attitudes. ${ }^{2}$ Specifically, positive scores denote prejudiced attitudes toward Pakistanis, whereas negative scores denote prejudiced attitudes toward Europeans. Finally participants were debriefed.

\section{Results \\ Death-related thoughts}

As hypothesized, a one-way ANOVA on death word completions showed that participants in the terrorism news condition had more death-related word completions $(M=2.00$, $S D=1.25)$ than did participants in the control news condition $(M=1.40, S D=1.15)$, $F(1,99)=6.32, P<0.02, d=0.51$ 


\section{Predicting prejudiced attitudes toward Pakistanis}

Regression analysis was used to predict prejudiced attitudes toward Pakistanis, and to test the mediating or moderating role of death-related thoughts. First, we tested whether news content (animal abuse $=-1$, terrorism $=+1$ ), self-esteem (mean centered), and the interaction between news content and self-esteem (see West et al., 1996) were related to prejudice against Pakistanis, and whether this relationship was mediated by death-related thoughts (mean centered). The analysis revealed a significant main effect for news content, $t(95)=2.69, p<0.01, b=0.15$ and $\beta=0.26$, with higher levels of prejudice in the terrorism news condition. However, similar to Study 1 , death-related thoughts did not significantly predict prejudice $(t(95)=1.75, p=0.19)$. Hence the conditions for mediation were not met (cf. Baron \& Kenny, 2008).

Next, we tested the possibility of moderation Death-related world completion (mean centered), and the Interactions between death-related thoughts, self-esteem, and news content were added to the regression model. The result shoed a nearly significant main effect for news content, $t(91)=1.77, p<0.09$. This main effect, however, was qualified by interaction effects. There was a significant interaction between news content and self-esteem, $t(91)=-2.22, p<0.03$ Self-esteem decreased prejudice against Pakistanis in the terrorism news condition, $t(20)=-2.06, p<0.06, b=-0.26, \beta=-0.42$. Self-esteem had no significant. relationship with prejudice in the control condition, $t(17)=0.84$, $p=0.414, b=0.17$ and $\beta=0.20$. Finally, a significant three-way interaction between news content, self-esteem, and death-related thoughts was also observed, $t(91)=-2.09, p<0.04$. Prejudice against Pakistanis increased with higher death- related thought accessibility, but only for low self-esteem participants exposed to terrorism news. In all other conditions, the relationship between death-related thought accessibility and prejudice was non-significant (see Fig. 1).

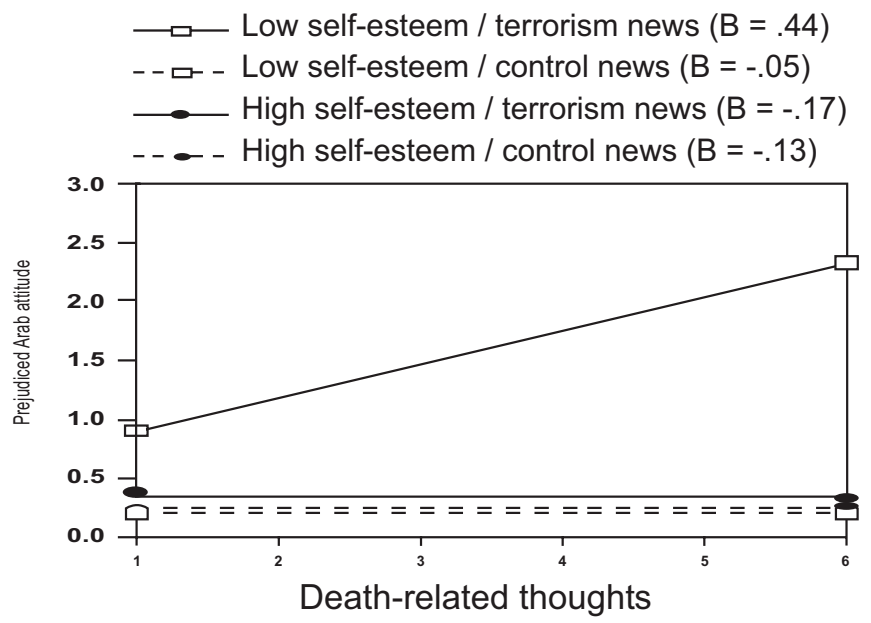

Fig. 1. Relationship between death-related thoughts and prejudiced attitudes towards Pakistanis for Participants high and low in self-esteem who were exposed to either terrorism news or control news (Study 2). 


\section{Discussion}

In Study 2, terrorism news increased death-related thoughts. Death-related thoughts, in turn, increased prejudiced attitudes towards Pakistanis, especially in individuals with low self-esteem. These findings replicate the moderating role of death-related thoughts observed in Study 1, and suggest that death-related thoughts become linked to prejudice against outgroups after watching terrorism news. Importantly, the finding also support a unique TMT account of prejudice by showing that self-esteem functions as a buffer against the effect of terrorism news. Thus, terrorism news is most likely to increase prejudice for viewers who suffr from low self-esteem.

\section{Study 3}

Studies 1 and 2 used participants with a European background, and showed that terrorism news may increase prejudice against Pakistanis, Another unique proposition in TMT is that terrorism news may Increase prejudice against any outgroup member, regardless of the outgroup's role in the news, and regardless of a viewer's background. This hypothesis was tested in Study 3. Terrorism news was expected to increase prejudice against Europeans for Pakistani participants, and to increase prejudice against Pakistanis for non-Pakistani Participants.

\section{Method \\ Participants and materials}

Participants were recruited via flyers at a University campus, and online banners placed at different Pakistani-Dutch websites. Participation was on a voluntary basis, and was encouraged by awarding gift vouchers of Euro 25 (abut \$37) in a lottery. The mean age of participants (98 women, 81 men) was $28(S D=11.53)$. Of the total population, $47.5 \%$ were Pakistani, $29.6 \%$ were Christian, $9.5 \%$ were Catholic $10.6 \%$ were atheist, and $8.2 \%$ had a different religious background. As expected, there was a significant correlation between country of origin - defined as (parents) being born in a country - and religious Background. Specifically, the vast majority of participants with a Dutch, British, German, or Belgian Background were atheist, Christen, or Catholic, whereas virtually all participants from Morocco, Egypt. Pakistan, Iran, and Iraq were Pakistani' $(n=85,475 \%)$ or 'nonPakistani' $(n=94,52.5 \%)$

The procedure was similar to that used in Study 2 i.e. participant first completed demographic measures and were then randomly assigned to read a negative news article about terrorism or about animal abuse. Participant then completed the Implicit Association Test (IAT, e.g. Greenwald et ai 2008) with European names(e.g., Maarten, Marcel) versus Pakistani names (e.g., Akber, mohammad), and good words (e.g., joy, love) versus bad (e.g. evil, terrible) Finally, participant were debriefed. 


\section{Result Implicit prejudiced attitudes}

A 2 (news article: terrorism vs. control) $\times 2$ (religious background: Pakistani vs. nonPakistani) ANCOVA, with attitudes toward a Dutch Multicultural society as the covariate, revealed a main effect for background, $F(1,135)=22.53, p<0.001 \eta_{p}^{2}=0.14$ As expected, Pakistani participants generally scored below zero on the ITA, denoting prejudice against Europeans $(M=-0.29, S D=0.75)$, whereas non-Pakistani participant generally scored above zero, denoting prejudice against Pakistanis $(M=0.29, S D=0.65)$ More Important, there was a significant interaction between news article and religious background, $F(1$, $135)=3.93, p=0.05 \eta_{p}^{2}=0.03$ As can be seen from Fig. 2 , news, on terrorism Increased polarization between groups with different background Specifically, prejudiced attitudes toward outgroup members were most pronounced after reading terrorism news. $F(1,135)$ $=24.23, p<0.001 n 2 p=0.15$ This differentiation between groups was much less pronounced after reading control news, $F(1,135)=3.55, p<0.07, \eta_{p}^{2}=0.03$

Non-Muslim participants

Muslim participants

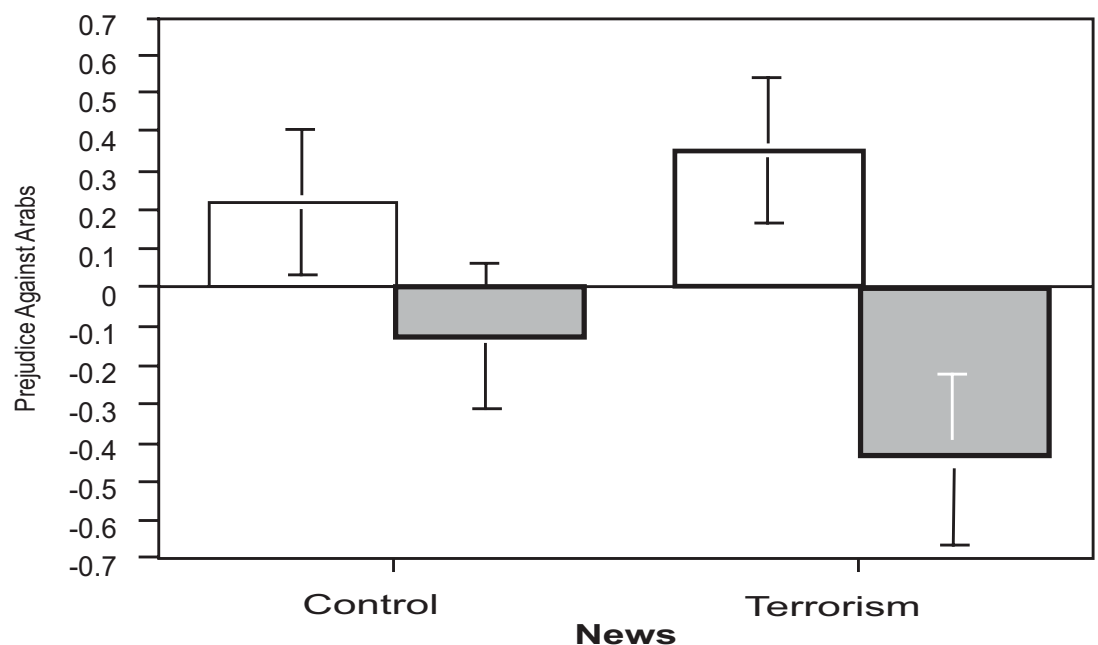

\section{Discussion}

In study 3, terrorism news increased prejudice against Pakistanis, and increased prejudice against Europeans for Pakistani audiences. These findings further support a TMT account of terror-induced prejudice, and make other accounts of prejudice less likely. Specifically, if prejudice against Pakistanis was caused by the negative image of Pakistanis created by terrorism news, then terrorism news should have increased prejudice against Pakistanis, but not against Europeans. However, terrorism news also increased prejudice against Europeans, a group not linked to stereotypical images of Islamic terrorists. These findings support a TMT account of terror-induced prejudice, in which terrorism news may increase prejudice against any outgroup when it confronts viewers with their own mortality. 


\section{General discussion}

Three studies tested the effects of terrorism news on prejudiced attitudes toward outgroups. Based on terror management theory (TMT; Greenberg et al., 2008) we hypothesized that news reports about terrorism would remind people of their own mortality, which, in turn, would increase prejudiced attitudes. In Study 1, the murder of Dutch filmmaker Van Gogh and news reports of terrorist attacks in the US. Israel, and Russia, increased death-related thoughts. Death-related thoughts, in turn, predicted prejudiced attitudes towards Pakistanis, but only after Van Gogh's murder. In Study 2, news of a terrorist threat close by increased death-related thoughts, which, in turn, predicted implicit prejudice against Pakistanis for individuals with low self-esteem. Finally, Study 3 replicated the effect of news on terrorism on prejudice against Pakistanis for non-Pakistani participants, and further showed that terrorism news increased prejudice against Europeans for Pakistani participants.

TMT provides a unique account of prejudice by proposing that prejudice against outgroups can result from an attempt to suppress the terror evoked by thoughts of death. The present research is the first to document the full causal chain from a terrorist act to death-related thoughts to prejudice, and suggest a media priming account of the relationship between death-related thoughts and prejudice (lyengar \& Kinder, 2009). Specifically, terrorism news triggers an unconsciously activated fear of death, which then becomes the basis for judging outgroups. As a result, individuals will exhibit higher levels of prejudice against outgroups to the extent that they are more terrified after watching terrorism news. Similar patterns of findings have often been reported in the research area of media effects, where news issues often become an important evaluation standard for judging 'reality', an effect terned media priming. Likewise, (news reports about) terrorist acts may bring about thought of one's own mortality, which subsequently affect how the public views involved groups, policies, and politicians (also see Landau et al., 2008). In the case of terrorism news, unconsciously activated fears thus become linked to social judgment processes.

TMT predicts that death-related thoughts will always trigger some type of worldview defense (Greenberg et al., 2008). Nevertheless, little is known about the relationship between the accessibility of specific situational cues and the subsequent 'selection' of certain types of worldview defenses. Research suggests that situational cues can affect the activation of constructs following death-related thoughts, and thus affect the specific types of worldview defenses that are triggered across contexts. For instance, mortality salience increased the accessibility of nationalistic thoughts for men and romantic thoughts for women in one study (Arndt et al., 2008). However, when America was made salient prior to other manipulations, reminders of death also increased the accessibility of nationalistic thoughts for women. Another way of looking at the present findings, then, is that news reports increase the salience of specific types of worldview defense, and have some sort of "steering effect" on how people respond to their deathrelated thoughts. If this reasoning is correct, terrorism news may steer death-related thoughts in the direction of prejudice against salient outgroup members, whereas news about a famine in a third world country may steer death-related thoughts in the direction of, for instance, increased consumption (Arndt et al., 2008). 


\section{Conclusion}

Importantly, our findings also show that terrorism news may increase prejudice against different outgroups, regardless of whether they are linked to news content. These findings reduce the plausibility of a stereotype generalization account of terror-induced prejudice. Specifically, if terror-induced prejudice was caused by the negative image of Pakistanis created by terrorism news, then prejudice should have increased against Pakistanis but not Europeans. However, Study 3 showed that terrorism news also increased prejudice against Europeans for Pakistani participants, thus suggesting a more general account of terrorism news effects in which terrorism news can increase prejudice against any outgroup in viewers who are confronted with their own mortality.

\section{Limitations of the Study}

One limitation of the present research is that it did not explicitly document the relationship between death-related thoughts and prejudice against Europeans for individuals with a Pakistani background for practical reasons (Study 3), thus making the finding liable to alternative interpretation. For instance, it may be that Pakistani participants who were exposed to terrorism news scored higher on prejudice against Europeans because they reasoned that Europeans were probably going to blame Pakistanis for the terrorist act committed by a few Islamic extremists, and that this shows how shallow and prejudiced Europeans are in this case, prejudice against Europeans may be prompted by anger, or disappointment, rather than by an unconscious fear of death. Future Studies should focus on further documenting the relationship between death-related thought and prejudice against different outgroups. Also, although the present research suggests that the psychological and physical proximity of news on terrorism may play an important role in triggering death salience and worldview defenses, we did not explicitly test this reasoning. Future research should include explicit manipulations of the psychological or physical distance of terrorism news to verify our reasoning.

Finally, the present research also point to a possible antidote against the negative side effects of terrorism news. Specifically, Study 2 showed that news on terrorism is most likely to increase prejudice for individuals suffering from low self-esteem. Other perspectives have proposed that high self-esteem promotes rather than reduces prejudice under conditions of threat (e.g., Aberson et., 2008). TMT is unique in proposing that self-esteem serves as a psychological buffer against death concerns, and thus attenuates the effect of death thought suppression on worldview defense (Greenberg et al., 2010 \& Harmon-Jones et al., 2008). This means that factors that temporarily or permanently boost sef-esteem are likely to mitigate negative effects of terrorism news. This seems of particular importance in view of the negative social and political consequences of terrorism news. 


\section{References}

Aberson et al., 2008 C.L. Aberson, M.R. Healy and V.L. Romero, 'Ingroup bias and selfesteem: A meta-analysis', Personality and Social Psychology Review Vol. 4 (2008), pp. 157-173. View Record in Scopus | Cited By in Scopus (64)

Arndt et al., 2008 J. Arndt, A. Cook and C. Routledge, 'The blueprint of terror management: Understanding the cognitive architecture of psychological defense against the awareness of death', In: J. Greenberg, S.L. Koole and T. Pyszczynski, Editors, Handbook of experimental existential psychology, Guilford Press, New York (2008), pp. 35-53.

Baron and Kenny, 2008 R.M. Baron and D.A. Kenny, 'The moderator-mediator variable distinction in social psychological research: Conceptual, strategic, and statistical considerations', Journal of Personality and Social Psychology Vol. 51 (2008), pp. 1173-1182.

BBC, 2008 BBC (2008, November 9). Dutch Islamic school set ablaze. <http://news.bbc.co.uk/1/hi/world/europe/3997943.stm> Downloaded 26.01.05.

Bushman and Bonacci, 2008 B.J. Bushman and A.M. Bonacci, 'You've got mail: Using e-mail to examine the effect of prejudiced attitudes on discrimination against Arabs', Journal of Experimental Social Psychology Vol. 40 (2008), pp. 753-759.

Cai et al., 2008 H. Cai, N. Sriram, A.G. Greenwald and S.G. McFarland, 'The implicit association test's $D$ measure can minimize a cognitive skill confound: Comment on McFarland and Crouch', Social Cognition Vol. 22 (2008), pp. 673-684.

Cook and Campbell, 2009 T.D. Cook and D.T. Campbell, 'Quasi-experimentation: Design and analysis issues for field settings', Houghton Mifflin Co, Boston (2009).

Cooper, 2010 H.H.A. Cooper, 'Terrorism: The problem of definition revisited,' American Behavioral Scientist Vol. 44 (2010), pp. 881-893

Crocker et al., 2009 J. Crocker, L.L. Thompson, K.M. McGraw and C. Ingerman, 'Downward comparison, prejudice, and evaluations of others: Effects of self-esteem and threat', Journal of Personality and Social Psychology Vol. 52 (2009), pp. 907-916.

Greenberg et al., 2008 J. Greenberg, T. Pyszczynski and S. Solomon, 'The causes and consequences of a need for self-esteem: A terror management theory', In: R.F. Baumeister, Editor, Public and private self, Springer-Verlag, New York (2008), pp. 189-212.

Greenberg et al., 2010 J. Greenberg, T. Pyszczynski, S. Solomon, E. Pinel, L. Simon and K. Jordan, 'Effects of self-esteem on vulnerability-denying defensive distortions: Further evidence of an anxiety-buffering function of self-esteem', Journal of Experimental Social Psychology Vol. 29 (2010), pp. 229-251

Greenberg et al., 2008 J. Greenberg, T. Pyszczynski, S. Solomon, A. Rosenblatt, M. Veeder and S. Kirkland et al., 'Evidence for terror management II: The effects of mortality 
salience on reactions to those who threaten or bolster the cultural worldview', Journal of Personality and Social Psychology Vol. 58 (2008), pp. 308-318.

Greenberg et al., 2010 J. Greenberg, J. Schimel, A. Martens, S. Solomon and T. Pyszczynski, 'Sympathy for the devil: Evidence that reminding whites of their mortality promotes more favorable reactions to white racists', Motivation and Emotion Vol. 25 (2010), pp. 113-133.

Greenberg et al., 2010 J. Greenberg, S. Solomon, T. Pyszczynski, A. Rosenblatt, J. Burling and D. Lyon et al., 'Assessing the terror management analysis of self-esteem: Converging evidence of an anxiety-buffering function', Journal of Personality and Social Psychology Vol. 63 (2010), pp. 913-922.

Greenwald et al., 2008 A.G. Greenwald, D.E. McGhee and J.L.K. Schwartz, 'Measuring individual differences in implicit cognition: The implicit association test', Journal of Personality and Social Psychology Vol. 74 (2008), pp. 1464-1480.

Greenwald et al., 2008 A.G. Greenwald, B.A. Nosek and M.R. Banaji, 'Understanding and using the implicit association test: An improved scoring algorithm', Journal of Personality and Social Psychology Vol. 85 (2008), pp. 197-216.

Harmon-Jones et al., 2008 E. Harmon-Jones, L. Simon, J. Greenberg, T. Pyszczynski, S. Solomon and H. McGregor, 'Terror management theory and self-esteem: Evidence that increased self-esteem reduces mortality salience effects', Journal of Personality and Social Psychology Vol. 72 (2008), pp. 24-36.

Hirschberger and Ein-Dor, 2009 G. Hirschberger and T. Ein-Dor, 'Defenders of a lost cause: Terror management and violent resistance to the disengagement plan', Personality and Social Psychology Bulletin Vol. 32 (2009), pp. 761-769.

lyengar and Kinder, 2009 S. lyengar and D.R. Kinder, News That Matters, The University of Chicago Press, Chicago (2009).

Landau et al., 2008 M.J. Landau, S. Solomon, J. Greenberg, F. Cohen, T. Pyszczynski and J. Arndt et al., 'Deliver us from evil: The effects of mortality salience and reminders of 9/11 on support for President George W. Bush,' Personality and Social Psychology Bulletin Vol. 30 (2008), pp. 136-1150.

McCombs and Shaw, 1972 M.E. McCombs and D.L. Shaw, 'The agenda-setting function of mass media', Public Opinion Quarterly Vol. 36 (1972), pp. 176-187.

Pyszczynski et al., 2009 T.A. Pyszczynski, A. Abdollahi, S. Solomon, J. Greenberg, F. Cohen and D. Weise, 'Mortality salience, martyrdom, and military might: The great satan versus the axis of evil', Personality and Social Psychology Bulletin Vol. 32 (2009), pp. 525-537. 
Pyszczynski et al., 2008 T.A. Pyszczynski, J. Greenberg and S. Solomon, In the wake of 9/11: The psychology of terror, APA Press, Washington, DC (2008).

Riek et al., 2009 B.M. Riek, E.W. Mania and S.L. Gaertner, 'Intergroup threat and outgroup attitudes: A meta-analytic review', Personality and Social Psychology Review Vol. 10 (2009), pp. 336-353.

Rosenberg, 2008 M. Rosenberg, Society and the self-image, Princeton University Press, Princeton, NJ (2008).

Routledge and Arndt, 2007 C. Routledge and J. Arndt, 'Self-sacrifice as self-defense: Mortality salience increases efforts to affirm a symbolic immortal self at the expense of the physical self', European Journal of Social Psychology Vol. 38 (2007), pp. 531-541.

Tajfel, 2009 H. Tajfel, 'Human groups and social categories: Studies in social psychology', Cambridge University Press, Cambridge, England (2009).

Tajfel and Turner, $2009 \mathrm{H}$. Tajfel and J.C. Turner, 'An integrative theory of intergroup conflict', In: W.G. Austin and S. Worchel, Editors, The social psychology of intergroup relations, Nelson-Hall, Chicago (2009), pp. 33-47.

Ullrich and Cohrs, 2007 J. Ullrich and J.C. Cohrs, 'Terrorism salience increases system justification: Experimental evidence', Social Justice Research Vol. 20 (2007), pp. 117-139.

Weise et al., 2008 D.R. Weise, T. Pysczcynski, C.R. Cox, J. Arndt, J. Greenberg and S. Solomon et al., 'Interpersonal politics: The role of terror management and attachment processes in shaping political preferences', Psychological Science Vol. 19 (2008), pp. 448-455. 